\title{
Ensino médio e educação profissional: reflexões para um currículo integrado ${ }^{1}$
}

\author{
Francinaide de Lima Silva Nascimento ${ }^{2}$ \\ Elizeu Costacurta Benachio ${ }^{3}$ \\ Roseane Idalino da Silva ${ }^{4}$
}

\section{Resumo}

Este artigo relaciona Educação Profissional e Ensino Médio a partir do Currículo Integrado, numa perspectiva politécnica, omnilateral. O objetivo é discutir e compreender a Educação Profissional e o Ensino Médio com Currículo Integrado, com vistas a contribuir para a superação da histórica dualidade entre trabalho manual/trabalho intelectual e formação propedêutica/formação profissional. A pesquisa bibliográfica e documental, com abordagem qualitativa, embasou-se em Kuenzer (2009), Moura (2012 e 2013a, 2013b), Saviani (2003), Frigotto, Ciavatta e Ramos (2012). Fundamentou-se na Constituição Federal (1988), Lei de Diretrizes e Bases da Educação Lei no 9.394/1996 e Decretos no 2.208/1997 e no 5.154/2004. A Educação Profissional e o Ensino Médio com Currículo Integrado são uma importante ação político-educacional para promover um modelo de educação e sociedade mais igualitário e equitativo à classe trabalhadora.

Palavras-chave: Educação Profissional; Ensino Médio; Currículo Integrado.

\section{High school and professional education: pathways to an integrated curriculum}

\section{Abstract}

This article deals with Secondary School Professional Education, Integrated Curriculum in a polytechnical and omnilateral perspective. It discusses Vocational Education to overcome the historical duality between manual and intellectual work, propaedeutic and vocational training. A bibliographical, documental research of qualitative nature was done based on Kuenzer (2009), Moura (2012; 2013), Saviani (2003), Frigotto, Ciavatta, Ramos (2012) and legal provisions: The Federal Constitution (1988), Law of Directives and Bases of National Education (Law 9,394/1996) and Decrees (2,208/1997/ 5,154/2004). It was seen that Vocational Training and Secondary Education-Integrated Curriculum is an important political and educational action; making Education and Society a role model more equal, equitable to working class.

Keywords: Professional Education; Secondary School; Integrated Curriculum.

\section{Introdução}

O trabalho é uma questão central na vida de todas as pessoas por se tratar de um requisito de sobrevivência. No entanto, em uma sociedade marcada por grandes diferenças entre as classes sociais, muitas são as configurações que o trabalho assume na vida de cada

\footnotetext{
${ }_{1}^{1}$ Pesquisa desenvolvida com fomento da Coordenação de Aperfeiçoamento de Pessoal de Nível Superior/CAPES.

2 PPGEP-IFRN, Natal-RN, francinaide.silva@ifrn.edu.br.

${ }^{3}$ PPGEP-IFRN, Natal-RN, elizeubenachio@gmail.com.

${ }^{4}$ PPGEP-IFRN, Natal-RN, roseaneidalino@gmail.com.
} 
trabalhador, em cada uma dessas classes. Diferenças que encontram ressonância na herança colonialista de dominação e exploração do trabalhador pelas elites dominantes. Aliado a isso, o desenvolvimento do capitalismo em âmbito mundial também colocou o trabalhador em uma condição servil e exploratória, tendo-o como instrumento a serviço da produtividade e lucratividade.

Nesse contexto, desde o processo de colonização portuguesa, o conhecimento sempre foi monopolizado pelas classes dominantes em detrimento das classes trabalhadoras, tornando-se, assim, privilégio para poucos, uma vez que representa objeto de poder (econômico, político, intelectual, social, científico, cultural etc.). Dessa forma, há uma sociedade dual na qual as classes privilegiadas têm acesso a um conhecimento mais elaborado para a manutenção e elevação do seu status de liderança e gerência, ao passo que as classes trabalhadoras populares não têm acesso às mesmas oportunidades.

A formação para o trabalho oferecida à classe trabalhadora, em muitos momentos da história, tem Ihe negado o direito a uma educação plena, restringindo-se, pois, a uma formação específica, técnica e operacional para a execução de determinadas atividades no contexto do setor produtivo capitalista. Essas diferenças entre classes cooperam para reproduzir e reforçar as desigualdades sociais, das quais as diferenças educacionais não são causa, mas consequência. Pensar em formas de superar essas desigualdades na perspectiva da construção de uma sociedade mais justa e igualitária para todos é o que nos motiva na realização deste trabalho, justificando-o.

Acreditamos que através da educação se poderá gradativamente promover essas mudanças, visto que isso refletirá diretamente na vida das pessoas. Para tanto, há que se pensar em um modelo educacional para os filhos da classe trabalhadora, que precisam começar a trabalhar cedo. Um modelo educacional que não seja restrito à formação para um determinado trabalho, mas que proporcione o desenvolvimento pleno do sujeito, a fim de que possa, mais do que aprender uma profissão técnica, ter as bases para a transformação da sua vida e da sua condição social. Nesse aspecto, a Educação Profissional Técnica de Nível Médio Integrada ao Ensino Médio apresenta-se como uma boa alternativa.

Dessa maneira, o objetivo deste trabalho é discutir e compreender a Educação Profissional e o Ensino Médio com Currículo Integrado, gerando reflexões importantes sobre o 
assunto a fim de diminuir a dualidade estrutural desse nível de ensino. Metodologicamente, o trabalho é desenvolvido a partir de pesquisa bibliográfica e documental, com abordagem qualitativa. Para melhor organização e compreensão dos conceitos e discussões desenvolvidos, este trabalho está dividido em duas seções. A primeira, intitulada Delineamentos HistóricoPolíticos sobre Ensino Médio e Educação Profissional, busca compreender a Educação Profissional, o Ensino Médio e a integração de ambos a partir de dispositivos legais e concepções teóricas de estudiosos do assunto. A segunda seção, intitulada Currículo Integrado: Apontamentos para uma Prática de Ensino, discute o papel e a concepção do currículo enquanto elemento estruturante da prática pedagógica, bem como a sua configuração para viabilizar a integração entre Educação Profissional e Ensino Médio.

\section{Delineamentos histórico-políticos sobre Ensino Médio e Educação Profissional}

Para falarmos de Educação Profissional e Currículo Integrado, suas relações e finalidades, faz-se necessário, em um primeiro momento, buscar alguns entendimentos acerca de Ensino Médio e Educação Profissional e seus principais desdobramentos. Para tal, convém reportarmo-nos aos aspectos históricos que caracterizam a gênese dessa modalidade educacional no Brasil. Segundo Kuenzer (2009, p.27), “a formação profissional como responsabilidade do Estado inicia-se no Brasil em 1909, com a criação de 19 escolas de artes e ofícios nas diferentes unidades da federação, precursoras das escolas técnicas federais e estaduais". Entretanto, essas escolas não tinham uma finalidade voltada para a formação profissional propriamente dita.

\footnotetext{
Essas escolas, antes de pretender atender às demandas de um desenvolvimento industrial praticamente inexistente, obedeciam a uma finalidade moral de repressão: educar, pelo trabalho, os órfãos, pobres e desvalidos da sorte, retirando-os da rua. Assim, na primeira vez que aparece a formação profissional como política pública, ela o faz na perspectiva moralizadora da formação do caráter pelo trabalho (KUENZER, 2009, p.27).
}

Percebe-se, desse modo, um caráter inicialmente assistencial da educação profissional, o qual obviamente se dirigia aos segmentos mais empobrecidos da sociedade. Posteriormente, 
foram desenvolvidas outras alternativas de formação de trabalhadores - como o curso rural e o curso profissional, que podiam ser sucedidos por outras formações em nível ginasial, a exemplo dos cursos normal, técnico agrícola e técnico comercial, voltados exclusivamente para o mundo do trabalho e sem habilitação para acesso ao Ensino Superior (KUENZER, 2009).

Evidencia-se, nesse sentido, o direcionamento dos jovens oriundos da classe trabalhadora a uma formação/preparação para a execução de atividades operacionais do setor produtivo. Uma vez que esses cursos não habilitavam o estudante para acesso ao ensino superior, ficavam tais jovens privados de qualquer possibilidade de ascensão social e/ou qualquer transformação que representasse a mudança de sua condição socioeconômica e cultural. Por outro lado, para os segmentos da elite, um encaminhamento distinto Ihes era reservado. Para eles, conforme Kuenzer (2009, p.27), “[...] havia outra trajetória: o ensino primário seguido pelo secundário propedêutico, completado pelo Ensino Superior, este sim dividido em ramos profissionais". Reforça-se, com isso, o caráter educacional desigual de uma sociedade fortemente marcada pelos estigmas do colonialismo, da exploração dos trabalhadores e dos privilégios de poucos.

Desse modo, a formação de trabalhadores e cidadãos no Brasil constituiu-se historicamente a partir da categoria dualidade estrutural, uma vez que havia uma nítida demarcação da trajetória educacional dos que iriam desempenhar as funções intelectuais ou instrumentais, em uma sociedade cujo desenvolvimento das forças produtivas delimitava claramente a divisão entre capital e trabalho traduzida no taylorismo/fordismo como ruptura entre as atividades de planejamento e supervisão por um lado, e execução por outro (KUENZER, 2009, p.27).

Essas características entre educação e mundo do trabalho ${ }^{5}$ fomentam a desigualdade e nutrem a sua reprodução, estabelecendo o monopólio do conhecimento para os segmentos mais bem possuídos da sociedade em detrimento dos mais empobrecidos. É nesses moldes que se configura a constituição do Ensino Médio e Profissional no Brasil. Essa realidade começa a ser mudada em 1961, quando, em meio a mudanças no mundo do trabalho, é promulgada a primeira Lei de Diretrizes e Bases da Educação Nacional - Lei no 4.024/1961 -, que, devido ao desenvolvimento dos setores secundário e terciário, bem como dos vários ramos profissionais,

${ }^{5} \mathrm{Em}$ alguns contextos usa-se a expressão "mercado de trabalho", que trataremos mais à frente.

Periódico Horizontes - USF - Itatiba, SP - Brasil - e019055 
passou a articular os ensinos propedêutico e profissional, reconhecendo, assim, a legitimidade de outros saberes, além dos propedêuticos tradicionais, para efeito de continuidade dos estudos (KUENZER, 2009).

Pela primeira vez, a legislação educacional reconhece a integração completa do ensino profissional ao sistema regular de ensino, estabelecendo-se a plena equivalência entre os cursos profissionalizantes e os propedêuticos, para fins de prosseguimento nos estudos (KUENZER, 2009, p.29).

Essa nova configuração, contudo, não resolveu a realidade dicotômica entre a formação geral propedêutica e a formação profissional.

$\mathrm{Na}$ prática, os currículos se encarregaram de mantê-la, pois a vertente propedêutica continuou privilegiando os conteúdos exigidos no acesso ao ensino superior, e os cursos profissionalizantes seguiram privilegiando os conteúdos vinculados às necessidades imediatas dos setores produtivos (MOURA, 2012, p.50).

Em 1971, ocorre a reforma da educação básica através da Lei no 5.692/1971, a qual estabeleceu a profissionalização compulsória como forma de atender à demanda por técnicos de nível médio diante da fase de industrialização brasileira - conhecida como "milagre brasileiro". Nesse período, de acordo com Kuenzer (2009, p.29), "a expectativa do desenvolvimento industrial com suas cadeias produtivas levava a antever significativa demanda por força de trabalho qualificada, notadamente no nível técnico". Além disso, havia a necessidade de conciliação com as classes populares, pois, segundo Moura (2012, p.50), "era crescente a demanda das classes populares por acesso a níveis mais elevados de escolarização, acarretando pressão pelo aumento de vagas no ensino superior". Essa política de profissionalização compulsória, porém, não vigorou devido a vários fatores. Um deles foi a concepção curricular, a qual, consoante Moura (2012, p.51), "empobrecia a formação geral em favor da profissionalização instrumental para o 'mercado de trabalho'”. Isso gerou "um acentuado movimento da classe média das escolas públicas para as escolas privadas, buscando a garantia de uma formação que permitisse a seus filhos continuar os estudos em nível superior" (MOURA, 2012, p.51). 
Dessa forma, retorna-se ao modelo anterior a 1971: escolas propedêuticas para as elites e profissionalizante para os trabalhadores; [...] Retorna à cena a velha dualidade estrutural, mesmo porque, originada na estrutura de classes, não pode ser resolvida no âmbito do projeto-político-pedagógico (KUENZER, 2009, p.30).

Nesse contexto, percebemos a nítida separação de classes e seus reflexos na esfera educacional, que não é causa, mas consequência dessa configuração de sociedade. Convém, aliás, ressaltar que essa disparidade faz parte do modelo de sociedade neoliberal. Nas palavras de Moura (2013a, p.112), "esse apartheid educacional é plenamente coerente com a sociedade neoliberal, pois, afinal, ela se nutre da desigualdade ao mesmo tempo em que a alimenta, já que essa é a substância vital da competitividade".

Ao examinarmos a Constituição da República Federativa do Brasil, há, em seu artigo 205, que "a educação, direito de todos e dever do Estado e da família, será promovida e incentivada com a colaboração da sociedade, visando ao pleno desenvolvimento da pessoa, seu preparo para o exercício da cidadania e sua qualificação para o trabalho" (BRASIL, 1988). Encontra-se aqui, portanto, a clara definição de três finalidades da educação, a saber: (1) o pleno desenvolvimento da pessoa; (2) o seu preparo para o exercício da cidadania; e (3) a sua qualificação para o trabalho. Reparemos que a formação para o trabalho é apenas uma das finalidades da educação. A plenitude da formação e do desenvolvimento humano passa por outros aspectos que não unicamente a formação para o trabalho. Assim, quando uma pessoa ou uma determinada classe social tem acesso a uma educação que apenas lhe serve de mecanismo de formação para o trabalho, estará sendo ela privada do seu desenvolvimento pleno enquanto pessoa ou classe, defendido, inclusive, constitucionalmente.

O inciso I do artigo 206 da Constituição Federal aponta como um dos princípios do ensino a "igualdade de condições para o acesso e permanência na escola" (BRASIL, 1988). Em uma sociedade desigual, dividida em classes, marcada pela dualidade entre formação propedêutica para as elites, na perspectiva do ensino superior, e formação profissional para a classe trabalhadora menos favorecida, na perspectiva do mercado de trabalho, esse princípio não é atendido. Mas não se trata apenas da questão do acesso. A permanência também acaba sendo prejudicada, pois muitas vezes o jovem necessita trabalhar, e tem dificuldade de conciliar trabalho e estudos, o que culmina por aumentar os índices da evasão. Conforme 
Moura (2013b, p.148): “A extrema desigualdade socioeconômica brasileira obriga grande parte dos filhos da classe trabalhadora a buscar, muito antes dos 18 anos de idade, a inserção no mundo do trabalho, visando complementar a renda familiar ou até a autossustentação".

Um jovem, nessa situação, é privado frequentemente, dadas as suas condições socioeconômicas, do acesso a uma educação mais elaborada, a qual the proporcione boas perspectivas de vida futura, nas várias dimensões que caracterizam as finalidades supracitadas pelo texto constitucional. Com um nível de educação deficitário, será menos valorizado, transformando-se em mão de obra barata a ser explorada pelo mercado de trabalho6 por intermédio da venda da sua força de trabalho por pouco mais que o necessário para a sua sobrevivência.

É diante dessa problemática que se faz necessário buscar ações político-educacionais na perspectiva da superação dessas desigualdades, de maneira que seja possível proporcionar uma educação digna para todos, principalmente para as classes menos favorecidas. Uma educação pensada para além do capital e com centralidade no ser humano. Uma educação que não separe formação intelectual e formação profissional, mas que integre trabalho, ciência, tecnologia e cultura, de modo que aqueles que precisam se preparar para o trabalho em um curto prazo o façam, tendo, porém, garantida também a formação que lhes ofereça as bases para o desenvolvimento pleno.

Ao pensar em um desenvolvimento pleno, nesse sentido, referimo-nos a uma formação omnilateral, politécnica.

A formação omnilateral é uma forma de conceber a educação para a classe trabalhadora. Baseada no pensamento de Marx, compreende as dimensões intelectual, física e tecnológica, constituindo-se, assim, em uma formação integral do ser humano, a qual abrange todas as dimensões da vida (MOURA, 2013b).

A politecnia é também uma denominação usada na perspectiva desse tipo de formação. Conforme Saviani (2003, p.136), “a noção de politecnia se encaminha na direção da superação

\footnotetext{
${ }^{6} \mathrm{~A}$ expressão "mercado de trabalho" é aqui entendida em um contexto no qual o trabalhador é tido como instrumento de produtividade e lucratividade pelo sistema produtivo capitalista, o qual detém os meios de produção e compra a força de trabalho (mão de obra) do trabalhador, que passa a ser visto como uma mercadoria nessa relação de caráter mercadológico. Para aprofundamento, sugerimos a leitura de Frigotto (2012, p.62), In.: FRIGOTTO, Gaudêncio; CIAVATTA, Maria; RAMOS, Marise (Orgs.). Ensino médio integrado: concepções e contradições. 3. ed. São Paulo: Cortez, 2012.
}

Periódico Horizontes - USF - Itatiba, SP - Brasil - e019055 
da dicotomia entre trabalho manual e trabalho intelectual, entre instrução profissional e instrução geral" através do "domínio dos fundamentos científicos das diferentes técnicas que caracterizam o processo de trabalho produtivo moderno" (SAVIANI, 2003, p.140).

A ideia de politecnia envolve a articulação entre trabalho intelectual e trabalho manual, implicando uma formação que, a partir do próprio trabalho social, desenvolva a compreensão das bases da organização do trabalho na nossa sociedade e que, portanto, nos permite compreender o seu funcionamento (SAVIANI, 2003, p.142).

Convém, agora, que analisemos algumas diretrizes legais que nortearam a organização do Ensino Médio e da Educação Profissional, visto que figuram entre as ações da política educacional para este nível e modalidade de ensino, para posteriormente discutirmos as possibilidades de construção e implementação de um projeto de educação na perspectiva politécnica, omnilateral.

Examinando a Lei de Diretrizes e Bases da Educação Nacional - LDB - (Lei no 9.394/1996), temos que o Ensino Médio, enquanto etapa final da educação básica, assume diferentes finalidades na vida dos estudantes que, diante de todos os desafios que se lhes impõem, vivem essa importante etapa de transição para a vida adulta. No artigo 35 da referida lei, estão elencadas as finalidades para essa etapa de ensino.

Art. 350 ensino médio, etapa final da educação básica, com duração mínima de três anos, terá como finalidades: I - a consolidação e o aprofundamento dos conhecimentos adquiridos no ensino fundamental, possibilitando o prosseguimento de estudos; II - a preparação básica para o trabalho e a cidadania do educando, para continuar aprendendo, de modo a ser capaz de se adaptar com flexibilidade a novas condições de ocupação ou aperfeiçoamento posteriores; III - o aprimoramento do educando como pessoa humana, incluindo a formação ética e o desenvolvimento da autonomia intelectual e do pensamento crítico; IV - a compreensão dos fundamentos científico-tecnológicos dos processos produtivos, relacionando a teoria com a prática, no ensino de cada disciplina (BRASIL, 1996).

Como vemos, esse conjunto de finalidades aponta para uma formação ampla, que contempla as várias dimensões da formação do estudante. É um ideal a ser perseguido por todas as esferas de ensino que oferecem Ensino Médio e a ser alcançado por todos os 
estudantes brasileiros. Contudo, a realidade social brasileira, marcada pelas desigualdades já abordadas, não permite a todos o mesmo direito ao alcance e efetivação de todas essas finalidades. Muitos estudantes acabam se restringindo à preparação básica para o trabalho, configurando-se, assim, como uma formação unilateral ${ }^{7}$ e não omnilateral.

Ocorre que um dos problemas encontrados por aqueles que precisam trabalhar cedo é a dificuldade em conciliar trabalho e estudos, levando muitas vezes à opção pelo trabalho em detrimento do estudo ou à procura por cursos de formação rápida, de caráter profissionalizante. Dessa forma, seria importante para essa categoria a existência de uma modalidade de educação que agregasse a formação profissional e a formação geral em um mesmo curso, com Currículo único numa perspectiva de formação politécnica, omnilateral.

Esta seria uma maneira de se começar a desconstruir a dicotomia entre formação profissional e propedêutica, e consequentemente promover uma educação digna e justa para todos. Todavia, em 1997, foi criado o decreto no 2.208, de 17 de abril de 1997, o qual regulamentava o $\S 2^{\circ}$ do art. 36 e os artigos 39 a 42 da Lei $n \div 9.394$, de 20 de dezembro de 1996, que estabelece as diretrizes e bases da educação nacional. Em suma, tratava-se de uma regulamentação acerca da educação profissional, e estabeleceu, entre outras coisas, a separação entre o Ensino Médio e a formação profissional. $O$ artigo 5o desse decreto determinava que "a educação profissional de nível técnico terá organização curricular própria e independente do ensino médio, podendo ser oferecida de forma concomitante ou sequencial a este" (BRASIL, 1997).

Dessa forma, não só era mantida a dualidade entre formação propedêutica e profissional, como também era reforçada e legalizada. Vale salientar que o referido decreto se deu no governo de Fernando Henrique Cardoso, o qual se caracterizou por ser de cunho fortemente neoliberal, e do qual as desigualdades foram parte integrante, com pouco esforço e prioridade em promover a inclusão e ascensão social.

Em 2004, já no governo de Luiz Inácio Lula da Silva, foi criado o decreto no 5.154, de 23 de julho de 2004, que revogou o decreto $n=2.208 / 1997$ e regulamentou novamente o § 20 do art. 36 e os arts. 39 a 41, da Lei no 9.394, de 20 de dezembro de 1996, estabelecendo as

\footnotetext{
7Uma formação "unilateral" deve ser entendida como aquela que se contrapõe à formação omnilateral. Enquanto a última busca atender a todas as dimensões da formação e desenvolvimento humano, a primeira nega essa integridade ao contemplar apenas uma dessas dimensões.
}

Periódico Horizontes - USF - Itatiba, SP - Brasil - e019055 
diretrizes e bases da educação nacional. O artigo 4ㅇ do decreto no 5.154/2004 definiu que "a educação profissional técnica de nível médio [...] será desenvolvida de forma articulada com o ensino médio" (BRASIL, 2004). Essa articulação é especificada no parágrafo 10 desse mesmo artigo do seguinte modo:

\begin{abstract}
§1ำA articulação entre a educação profissional técnica de nível médio e o ensino médio dar-se-á de forma: I-integrada, oferecida somente a quem já tenha concluído o ensino fundamental, sendo o curso planejado de modo a conduzir o aluno à habilitação profissional técnica de nível médio, na mesma instituição de ensino, contando com matrícula única para cada aluno; IIconcomitante, oferecida somente a quem já tenha concluído o ensino fundamental ou esteja cursando o ensino médio, na qual a complementaridade entre a educação profissional técnica de nível médio e o ensino médio pressupõe a existência de matrículas distintas para cada curso, [...]; III-subsequente, oferecida somente a quem já tenha concluído o ensino médio (BRASIL, 2004).
\end{abstract}

Logo, cria-se, a partir desse decreto, especialmente pela forma integrada de articulação entre Ensino Médio e Educação Profissional, a possibilidade de o Ensino Médio conferir também a habilitação técnica. Com isso, permite-se uma organização curricular para os cursos cuja estrutura aponte para uma formação na perspectiva politécnica, omnilateral. Frigotto, Ciavatta e Ramos (2012, p.43) destacam que "se a preparação profissional no ensino médio é uma imposição da realidade, admitir legalmente essa necessidade é um problema ético". Portanto, essa regulamentação trazida pelo decreto $\mathrm{n}$ - 5.154/2004 é mais do que justa e necessária na busca da construção de um projeto de educação integral ${ }^{8}$ para todos, tendo em vista a superação das desigualdades já mencionadas.

A possibilidade de integração, no entanto, não deve ser entendida como a solução cabal da questão da dualidade entre formação profissional e propedêutica aqui discutida, mas a viabilidade da construção de um projeto de educação que caminha nessa direção. Segundo Moura (2013b, p.148-149), o decreto no 5.154/2004 "possibilita a integração do ensino médio aos cursos técnicos, numa perspectiva que não se confunde completamente com a politecnia,

\footnotetext{
${ }^{8}$ Entenda-se aqui "educação integral" não no sentido temporal, mas uma educação não compartimentada, que tenha superado ou que esteja na busca da superação da separação entre trabalho manual/trabalho intelectual, cultura técnica/cultura geral e que busque superar a visão do homem como mão-de-obra, como força de trabalho do capital, valorizando-o enquanto ser humano com direito a uma formação que the proporcione o seu desenvolvimento pleno.
}

Periódico Horizontes - USF - Itatiba, SP - Brasil - e019055 
mas que aponta para o seu direcionamento por conter os princípios de sua construção".

O Ensino Médio Integrado, como passa a ser chamada a Educação Profissional Técnica de Nível Médio Integrada ao Ensino Médio, constitui-se, portanto, como um projeto de educação na perspectiva politécnica que visa a diminuir as distâncias entre o tipo de educação (desigual) das diferentes classes sociais. Busca-se, sobretudo, ofertar uma formação mais digna e ampla para aqueles que precisam se inserir no mundo do trabalho em um curto prazo, garantindo também a formação geral.

Entretanto, há que se entender essa modalidade formativa como transitória, pois o que se almeja é a superação das desigualdades e a construção de uma sociedade em que os jovens tenham iguais oportunidades aos diferentes níveis educacionais e no mundo do trabalho. Obviamente que essas diferenças são profundas e estão arraigadas nas condições socioeconômicas e culturais das diferentes classes sociais, e cuja superação não se dá simplesmente no plano curricular da educação.

Kuenzer (2009) afirma que a elaboração de uma nova concepção de formação não é uma questão pedagógica, porém sim uma questão política. Para ela, "a dualidade estrutural tem suas raízes na forma de organização da sociedade, que expressa as relações entre capital e trabalho; pretender resolvê-la na escola, através de uma nova concepção, ou é ingenuidade ou é má fé" (KUENZER, 2009, p.35).

Contudo, não podemos negar que a possibilidade de integração da Educação Profissional e o Ensino Médio representa um significativo e necessário avanço na perspectiva da formação politécnica, omnilateral, da superação das desigualdades e da construção de um novo tipo de sociedade com novas relações entre capital e trabalho, com mais dignidade humana e justiça social. Conforme Frigotto, Ciavatta e Ramos (2012, p.43), “o ensino médio integrado ao ensino técnico, sob uma base unitária de formação geral, é uma condição necessária para se fazer a 'travessia' para uma nova realidade".

Nesse sentido, entendemos o Ensino Médio Integrado, como assim passou a ser chamado, em consonância com Ciavatta:

No caso da formação integrada ou do ensino médio integrado ao ensino técnico, queremos que a educação geral se torne parte inseparável da educação profissional em todos os campos onde se dá a preparação para o

Periódico Horizontes - USF - Itatiba, SP - Brasil - e019055 
trabalho: seja nos processos produtivos, seja nos processos educativos, como formação inicial, como o ensino técnico, tecnológico ou superior. Significa que buscamos enfocar o trabalho como princípio educativo, no sentido de superar a dicotomia trabalho manual/trabalho intelectual, de incorporar a dimensão intelectual ao trabalho produtivo, de formar trabalhadores capazes de atuar como dirigentes e cidadãos (CIAVATTA, 2012, p.84).

Diante das abordagens até aqui realizadas e do entendimento dessa nova concepção de formação, faz-se necessário discutir de que forma esse modelo de formação será organizado pedagogicamente em termos curriculares. "Faz-se necessário deixar claro que currículo está sendo, aqui, considerado como hipóteses de trabalho e de propostas de ação didática, que serão definidas para serem desenvolvidas na prática educativa" (MACHADO, 2010, p.81). É isso que abordaremos na próxima seção.

\section{Currículo integrado: apontamentos para uma prática de ensino}

As concepções sobre currículo escolar se modificaram no decorrer dos anos, e ele, o currículo escolar, deixou de ser apenas uma área que se preocupava com estruturas curriculares para se preocupar também com o fazer dessas estruturas e as suas influências diretas ou indiretas na formação do estudante, com base em concepções sociológicas, filosóficas e epistemológicas.

De acordo com Moreira e Silva (2009, p.7-8), “o currículo não é um elemento inocente e neutro de transmissão desinteressada do conhecimento social”, reforçando a dimensão de que ele contribui com os processos formativos, com base nas três finalidades já mencionadas anteriormente da Educação. Dessa maneira, o desenvolvimento pleno de um sujeito - preparálo para exercer a cidadania como corresponsável pelo processo e prepará-lo para o mundo do trabalho - requer compreender que o fazer pedagógico está pautado em interesses de classes, de ações de poder e de saberes julgados mais significativos para determinado grupo de estudantes. "O currículo está implicado em relações de poder, o currículo transmite visões sociais particulares e interessadas, o currículo produz identidades individuais e sociais particulares" (MOREIRA; SILVA, 2009, p.8).

Esse processo organizacional do currículo se orienta em movimentos históricos e sociais 
que embasam ações presentes até os dias atuais na construção do cotidiano de nossas escolas, reforçando a ideia de que ele pode ser um instrumento de controle social (MOREIRA; SILVA, 2009). Nessa dimensão, podemos destacar o seguinte:

[...] o conhecimento corporificado como currículo educacional não pode ser mais analisado fora de sua constituição social e histórica. Não é mais possível alegar qualquer inocência a respeito do papel constitutivo do conhecimento organizado em forma curricular e transmitido nas instituições educacionais (MOREIRA; SILVA, 2009, p.20).

A educação se torna um dos caminhos para que as classes dominantes incorporem as suas ideias e concepções, enfatizando diariamente que as condições que as classes trabalhadoras estão vivenciando são naturais, que fazem parte do processo de sobrevivência da espécie. Assim, aceleram a entrada de jovens cada vez mais cedo no mercado de trabalho, ofertando cursos aligeirados, os quais somente preparam para execução de uma tarefa, reproduzindo a estrutura social. De acordo com Moreira e Silva (2009, p.21-22) "essas ideias seriam diferencialmente transmitidas, na escola, às crianças das diferentes classes: uma visão de mundo apropriada aos que estavam destinados adominar, outra aos que se destinavam às posições sociais subordinadas".

Nessa conjuntura, o currículo é organizado para atender a diferentes interesses em um grupo social, levando por vezes os seus atores a realizarem ações que não concordam até mesmo sem perceber que estão contribuindo com esse processo de reprodução de uma organização social. Para romper com esse aspecto, é necessária uma compreensão do fazer pedagógico em suas dimensões políticas, sociais e de interesses. "Essa transmissão da ideologia estaria centralmente a cargo daquelas matérias escolares mais propícias ao 'ensino' de ideias sociais e políticas" (MOREIRA; SILVA, 2009, p.22), o que nos leva à compreensão do constante questionamento da permanência de determinadas disciplinas ministradas ou de determinadas estratégias metodológicas realizadas nos espaços escolares.

Configuram-se, no espaço escolar, movimentos que reforçam valores e conhecimentos, construindo e reconstruindo as culturas estabelecidas. Isto porque, 
Por um lado, o currículo, enquanto definição "oficial" daquilo que conta como conhecimento válido e importante, expressa os interesses dos grupos e classes colocados em vantagem em relações de poder. Desta forma, o currículo é expressão das relações sociais de poder (MOREIRA; SILVA 2009, p.29).

Essas relações são vivenciadas no espaço escolar em situações do seu cotidiano, que estão além das disciplinas que são ensinadas, mas também nas suas estratégias de ensino, nas relações que são estabelecidas na escola, no modelo de formação para além da sala de aula, nos corredores dessa vivência em sociedade, que molda a favor de uma determinada concepção de Educação.

A organização curricular por disciplina faz parte desse processo de formação. Às vezes, isso não forma em sua integralidade, não traz à compreensão de que o conhecimento é integrado e não desconexo como é posto, não leva em consideração todo um contexto social, político e cultural. O desafio de romper com a disciplinaridade é um dos primeiros passos para se pensar em uma Formação Humana Integral ${ }^{9}$.

Essa disciplinaridade constitui, talvez, o núcleo que primeiro deva ser atacado em uma estratégia de desconstrução da organização curricular existente. Temse veiculado, com insistência, nesse contexto, o papel da chamada "interdisciplinaridade". Apenas de sua aparência transgressiva, é preciso reconhecer que o movimento da interdisciplinaridade supõe a disciplinaridade, deixando, assim, intacto exatamente o fundamento da presente estrutura curricular (MOREIRA; SILVA 2009, p.32).

Esse caminho ainda não se constitui como o ideal, mas se apresenta como possibilidade de superação dessa fragmentação no ensino. Reforçamos ainda que "as disciplinas tomaram um caráter abstrato e fixo próprio dos currículos fragmentados que criticamos frequentemente e que buscamos superar, no plano possível, com a proposta do currículo integrado" (RAMOS, 2012, p.112).

Diante desse contexto, na busca por emancipação do estudante trabalhador, o Ensino Médio Integrado passa a ser organizado como uma tentativa a um ideal de Formação Humana Integral, inspirado nas ideias da escola unitária de Gramsci, e "pressupõe que todos tenham acesso aos conhecimentos, à cultura e às mediações necessárias para trabalhar e para produzir

${ }^{9} \mathrm{~A}$ "Formação Humana Integral” deve ser entendida na mesma perspectiva da formação politécnica, omnilateral.

Periódico Horizontes - USF - Itatiba, SP - Brasil - e019055 
a existência e a riqueza social" (RAMOS, 2008, p.2). Visa-se articular o interesse dos estudantes com uma sociedade em processo constante de modificação. O Currículo Integrado é marcado pela relação entre trabalho, ciência, tecnologia e cultura, sendo esta articulação a base das ações desenvolvidas nas escolas que pretendem atuar nessa perspectiva. Nesse sentido:

O trabalho compreendido como realização humana inerente ao ser (sentido ontológico) e como prática econômica (sentido histórico associado ao respectivo modo de produção); a ciência compreendida como os conhecimentos produzidos pela humanidade que possibilita o contraditório avanço produtivo; e a cultura, que corresponde aos valores éticos e estéticos que orientam as normas de conduta de uma sociedade (RAMOS, 2008, p.3).

Um dos maiores desafios é conseguir articular a integração entre áreas de conhecimento que historicamente foram configuradas por meio de disciplinas, o que deixou o trabalho pedagógico dividido em partes. Elas até poderiam convergir entre si, mas, por uma questão de organização curricular, essa feitura não é comum, ampliando ainda mais o distanciamento entre a construção do conhecimento integrado.

Os conteúdos de ensino foram construídos ao longo da história do ser humano. Com eles, é possível ressignificar conhecimentos prévios e ampliar conhecimentos já existentes, algo que nos leva a refletir criticamente sobre o processo de organização curricular que está arraigado de influências ideológicas, de cultura e de relações de poder. Para Ramos (2012, p.108):

Apreender o sentido dos conteúdos de ensino implica reconhecê-los como conhecimentos construídos historicamente e que se constituem, para o trabalhador, em pressupostos a partir dos quais se podem construir novos conhecimentos no processo de investigação e compreensão do real.

Reforça-se, dessa maneira, que o conhecimento trabalhado no espaço escolar irá ou não contribuir para uma formação mais crítica e emancipadora desse estudante. 0 processo de construção dos conhecimentos tem como base a dimensão ontológica do trabalho, ou seja, "o trabalho no seu sentido mais amplo, como realização e produção humana, mas também o trabalho como práxis econômica" (RAMOS, 2008, p.2), na perspectiva de possibilitar o acesso aos conhecimentos construídos pelos homens. O trabalho é uma característica essencial ao ser humano, como processo de sobrevivência da espécie. É por meio dele que o ser se faz humano 
e nesse processo se dá a produção de conhecimento e cultura. Para Ramos (2008, p.6), "[...] o trabalho é tomado como princípio educativo da educação básica no sentido de que o ensino deve explicitar a relação entre a produção do conhecimento e o avanço das forças produtivas", levando a uma reflexão sobre o trabalho assalariado em suas dimensões e imposições na sociedade. Ao longo do processo formativo, a dimensão trabalho ganha outras conjunturas, passando a ser posto como trabalho assalariado (RAMOS, 2012), acarretando uma preocupação do estudante com um processo formativo que o faça ter atributos para estar imerso no contexto social como trabalhador.

Nesse contexto, a escola torna-se um dos espaços de formação dentro dessa perspectiva do trabalho, e o currículo escolar passa a ser fundamento dessa dimensão e se aprofunda na tentativa de garantir uma integração do conhecimento. Para Ramos, (2012, p.114, grifos do autor), "[...] currículo integrado tem sido utilizado como tentativa de contemplar uma compreensão global do conhecimento e de promover maiores parcelas de interdisciplinaridade na sua construção", o que nos leva a compreender que o processo de organização do Currículo Integrado tenta romper com essa perspectiva de ensino fragmentado.

Tavares et al. (2016, p.173) reforça ainda: “O Currículo Integrado é uma tentativa de possibilitar aos estudantes o acesso aos conhecimentos científicos e culturais da humanidade, para que possam ter acesso a espaços para o desenvolvimento da experimentação e das práticas de estudo e investigação".

Com essas dimensões, podemos afirmar que o Currículo Integrado no Ensino Médio que oferta Educação Profissional irá sistematizar uma formação que leve em consideração a totalidade dos sujeitos envolvidos nesse processo e que terá como base a tentativa de garantir uma formação significativa para esses alunos. É válido salientar que, na composição do currículo, os eixos trabalho, ciência, tecnologia e cultura devem estar alinhados para garantir que a formação do aluno atente para a formação omnilateral, a qual objetiva formar os sujeitos em todas as suas dimensões.

Sobre isso, Tavares et al. (2016, p.178) aponta: "Por essa razão, trabalho, ciência, tecnologia e cultura são instituídos como base da proposta e do desenvolvimento curricular no Ensino Médio de modo a inserir no contexto escolar o diálogo permanente com as diferentes áreas do conhecimento". 
Todos esses apontamentos buscam a organização de um Currículo Integrado que visa a formar um estudante capaz de questionar a sua realidade dentro de vários aspectos. Ora, será esse estudante que deverá levantar pontos a serem observados para a construção de uma sociedade que atenda aos interesses de todos.

Em conformidade com Ciavatta (2012, p.94):

\begin{abstract}
A formação integrada entre o ensino geral e a educação profissional ou técnica (educação politécnica ou, talvez, tecnológica) exige que se busquem os alicerces do pensamento e da produção da vida além das práticas de educação profissional e das teorias da educação propedêutica que treinam para o vestibular.
\end{abstract}

O desafio do Ensino Médio Integrado à Educação Profissional é garantir que a formação não seja pautada apenas na formação técnica, mas leve em consideração todas as dimensões para uma formação integral. Alguns caminhos são pensados nessa perspectiva. Primeiro, devemos salientar que a formação integrada deve ser um projeto social (CIAVATTA, 2012) no qual todos os envolvidos no processo compreendam que essa formação precisa se preocupar com a formação humana para o mundo do trabalho. Também é preciso garantir esse processo por meio de Leis que irão reger as suas implantações em todas as modalidades.

Para que o caminho da realização desse Ensino Médio Integrado se torne sólido, é importante considerar a participação dos gestores e professores na construção desse ideal, e, além disso, a busca por uma organização das práticas de ensino e dos currículos. Ciavatta (2012, p.100) reforça:

Tanto os processos de ensino-aprendizagem, como de elaboração curricular devem ser objeto de reflexão e de sistematização do conhecimento através das disciplinas básicas e dos conteúdos, inclusive com o aproveitamento das lições que os ambientes de trabalho podem proporcionar (visitas, estágios etc.).

Devemos ter em conta também as articulações entre os estudantes e a comunidade escolar, pois "as experiências de formação integrada não se fazem no isolamento institucional" (CIAVATTA, 2012, p.100). Todo o processo formativo desses estudantes passa por uma demanda familiar e social, cabendo à instituição o constante processo de orientação e de 
escuta, reforçando a dinâmica da gestão democrática, possibilitando ações mais coletivas e inovações pedagógicas.

Para que os processos formativos desses alunos atendam a uma Formação Humana Integral, é necessário compreender os contextos históricos, políticos, epistemológicos que embasam o Ensino Médio Integrado. Ademais, compreender que as escolhas de como realizar essa formação perpassam por uma reflexão das questões de poder, de ideologias e de cultura, não apenas de definição de estruturas curriculares.

Cabe destacar, ainda, que a construção de um projeto de formação humana integral demanda a existência de recursos, visto que não se faz educação sem investimentos (CIAVATTA, 2012). Nesse contexto, consideramos o cenário brasileiro bastante adverso para o campo educacional, sobretudo após a aprovação da Emenda Constitucional 95/2016, que congela investimentos por 20 anos, e pela política de contingenciamento de gastos adotada pelo atual governo, medidas essas que impactam diretamente a qualidade da educação.

\section{Considerações finais}

Sendo o trabalho uma questão primordial de sobrevivência do ser humano e considerando as grandes desigualdades sociais existentes no Brasil que se refletem no âmbito educacional, consideramos que é dever de todo profissional da educação verdadeiramente comprometido com a justiça social refletir sobre essa temática na busca de um modelo educacional que ofereça uma formação digna para todos, independentemente da sua condição social.

O conhecimento transforma a vida das pessoas conferindo-Ihes maior poder econômico, político, social, intelectual, científico, cultural etc., e não se pode falar em justiça social enquanto esse empoderamento se dá de forma desigual, mantendo e reproduzindo desigualdades, criando dominantes e dominados. Obviamente que as diferenças de classes sempre vão existir, porém queremos que não sejam negadas às classes menos favorecidas, àqueles que dependem do trabalho, o mesmo direito e acesso a uma educação plena que thes proporcione a formação profissional aliada a uma formação geral, que Ihes permita a sua inserção na sociedade e no mundo do trabalho com autonomia, consciência crítica e política, perspectivas de crescimento pessoal e profissional, protagonismo e capacidade de transformação. 
Queremos que o jovem que depende do trabalho (aqui nos referindo àquele que precisa começar a trabalhar cedo em sua vida) tenha acesso a uma formação plena e não restritamente profissionalizante, pois a natureza da sua formação condicionará substancialmente os rumos da sua vida. O ideal a ser alcançado seria aquele em que o jovem pudesse cursar toda a Educação Básica e realizar a sua formação profissional posteriormente em nível superior, mas sabemos que a realidade se mostra bem diferente. É um ideal a ser alcançado, quiçá em uma sociedade do futuro, que ainda precisa ser construída. Enquanto se caminha nessa direção, fazem-se necessárias ações político-educacionais para o tempo presente, as quais busquem superar a fragmentação do ensino, a separação entre trabalho manual e trabalho intelectual e suas respectivas formações. Um modelo de educação pensado, estruturado e desenvolvido na perspectiva politécnica, omnilateral.

Nesse sentido, a Educação Profissional Técnica de Nível Médio na modalidade Integrada ao Ensino Médio se apresenta como uma boa alternativa, ao unir em um mesmo curso com Currículo único - o qual chamamos "Currículo Integrado" - a Formação Profissional e a formação referente ao Ensino Médio Regular. Isso busca eliminar a fragmentação acima referida, capacita o jovem para o mundo do trabalho e proporciona as bases para o seu crescimento, seja na continuidade dos estudos, seja na realização de outros projetos de seu interesse. Ainda não é, pois, esse o ideal de educação a ser alcançado, porém consideramos uma proposta possível para o tempo presente. Com ela, diminuem-se as distâncias educacionais entre as diferentes classes sociais apontadas no decorrer deste artigo.

Por fim, entendemos que o Currículo é um elemento central nessa construção, uma vez que é ele que define os caminhos que serão seguidos para a concretização da ação pedagógica. É ele que será o portador de uma concepção de formação, de homem e de sociedade, por isso há que ser bem pensado, planejado e estruturado para que, em articulação com o Projeto Político Pedagógico, possa traduzir para a prática esse modelo de educação aqui defendido.

\section{Referências}

BRASIL. Constituição Federal (1988). Constituição da República Federativa do Brasil. Disponível em: http://www.planalto.gov.br/ccivil_03/Constituicao/Constituicao.htm. Acesso em: 16 jun. 2018. 
BRASIL. Decreto no 2.208, de 17 de abril de 1997. Regulamenta o § 20 do art. 36 e os arts. 39 a 42 daLei no 9.394, de 20 de dezembro de 1996, que estabelece as diretrizes e bases da educação nacional. Disponível em: http://www.planalto.gov.br/ccivil_03/decreto/D2208.htm. Acesso em: 18 jun. 2018.

BRASIL. Decreto no 5.154, de 23 de julho de 2004. Regulamenta o § 20 do art. 36 e os arts. 39 a 41 da Lei no 9.394, de 20 de dezembro de 1996, que estabelece as diretrizes e bases da educação nacional, e dá outras providências. Disponível em: http://www.planalto.gov.br/ccivil_03/_Ato2004-2006/2004/Decreto/D5154.htm.Acesso em: 18 jun. 2018.

BRASIL. Lei no 9.394, de 20 de dezembro de 1996. Dispõe sobre as diretrizes e bases da educação nacional. Disponível em: http://www.planalto.gov.br/ccivil_03/leis/L9394.htm. Acesso em: 17 jul. 2018.

CIAVATTA, M. A formação integrada: a escola e o trabalho como lugares de memória e identidade. In: FRIGOTTO, G.; CIAVATTA, M.; RAMOS, M. (Orgs.). Ensino médio integrado: concepções e contradições. 3. ed. São Paulo: Cortez, 2012.

FRIGOTTO, G.; CIAVATTA, M.; RAMOS, M. A gênese do decreto n‥ 5.154/2004: um debate no contexto controverso da democracia restrita. In: FRIGOTTO, G.; CIAVATTA, M.; RAMOS, M. (Orgs.). Ensino médio integrado: concepções e contradições. 3. ed. São Paulo: Cortez, 2012.

KUENZER, A. (Org). Ensino médio: construindo uma proposta para os que vivem do trabalho. São Paulo: Cortez, 2009.

MACHADO, L. Ensino médio e técnico com currículos integrados. In: MOLL, J. et al. Educação profissional e tecnológica no Brasil contemporâneo: desafios, tensões e possibilidades. Porto Alegre: Artmed, 2010.

MOREIRA, A. F. B.; SILVA, T. T. Sociologia e teoria crítica do currículo: uma introdução. In: MOREIRA, A. F. B.; SILVA, T. T. (Orgs.). Currículo, cultura e sociedade. 11. ed., São Paulo: Cortez, 2009.

MOURA, D. H. Políticas públicas para educação profissional técnica de nível médio nos anos 1990 e 2000: limites e possibilidades. In: OLIVEIRA, R. (Org.). Jovens, ensino médio e educação profissional: políticas públicas em debate. Campinas/SP: Papirus, 2012.

MOURA, D. H. Mudanças na sociedade brasileira dos anos 2000 limitadas pela hegemonia do neoliberalismo: implicações para o trabalho e para a educação. In: MOURA, D. H. (Org.). Produção de conhecimento, políticas públicas e formação docente em educação profissional. Campinas/SP: Mercado de Letras, 2013a.

MOURA, D. H. Ensino médio e educação profissional no brasil nos anos 2000: movimentos 
contraditórios. In: MOURA, D. H. (Org.). Produção de conhecimento, políticas públicas e formação docente em educação profissional. Campinas/SP: Mercado de Letras, 2013b.

RAMOS, M. N. Concepção do ensino médio integrado. Disponível em:

https://tecnicadmiwj.files.wordpress.com/2008/09/texto-concepcao-do-ensino-mediointegrado-marise-ramos1.pdf. Acesso em: 19 nov. 2019.

RAMOS, M. Possibilidades e desafios na organização do currículo integrado. In: FRIGOTTO, G.; CIAVATTA, M.; RAMOS, M. (Orgs.). Ensino médio integrado: concepções e contradições. 3. ed. São Paulo: Cortez, 2012.

SAVIANI, D. O choque teórico da politecnia. Educação, Trabalho e Saúde. v.1. Rio de Janeiro: EPSJV/FIOCRUZ, 2003, p.131-152.

TAVARES, A. M. B. N. et al. Educação profissional e currículo integrado a partir de eixos estruturantes no ensino médio. In: MOURA, D. H. Educação profissional: desafios teóricometodológicos e políticas públicas. Natal: IFRN, 2016.

\section{Agradecimentos}

À Coordenação de Pessoal de Nível Superior/CAPES pela concessão de bolsa de pesquisa para o Curso de Mestrado no PPGEP-IFRN.

Recebido em maio de 2019.

Aprovado em outubro de 2019. 